\title{
O ideal sanitário e de beleza contido nos estatutos de 1912 da Câmara Municipal da Villa Divinópolis
}

\section{The sanitarium and beauty idealism in the statutes of 1912 in the Divinópolis Village Council Office}

\author{
Batistina Maria de Sousa Corgozinho
}

Socióloga, doutora em Educação (UFMG), pós-doutoranda no Centro de Memória-Unicamp e professora da FUNEDI/UEMG bcorgozinho@funedi.edu.br

\section{Resumo:}

Estudo sobre aspectos da política sanitarista anunciada no documento "Estatutos da Câmara Municipal da Villa Divinópolis contendo também o seu Regimento Interno", aprovado em 20 de novembro de 1912, momento de organização da vida urbana nessa cidade do centro-oeste mineiro para ser aplicado buscando a aquisição de uma cultura urbana pelos seus habitantes.

Palavras-chave: Estatuto; Sanitarismo; Urbanização; Cidade; Cultura urbana

\section{Abstract:}

Study on aspects of public health policy announced in document "Statute of the City Council of Villa Divinópolis containing also its Internal Rules"; adopted on November 20,1912, moment of organization of urban life in this city in central-west of the Minas Gerais state, to be applied to seek the acquisition of an urban culture by its inhabitants.

Keywords: Statute; Sanitary, Urbanization; City, Urban culture 
7 definiçáo de um estatuto, conformando as relaçóes sociais, revela práticas sociais existentes ou reflete aspiraçóes em relação ao que deveria vir a ser a realidade social? Provavelmente muito mais um ideal a ser alcançado. Este estudo trata sobre as normas sanitárias instituídas pelo poder político local, em relação à vida urbana, em aspectos como higiene domiciliar, construçôes, alimentação pública, precauções contra moléstias transmissíveis, limpeza pública, doentes mentais, medidas preventivas de danos, medidas em relação à mendicância, o sistema de abastecimento de água canalizada, funcionamento do matadouro e açougues, construçóes urbanas e vias públicas. A quem visa as açôes do poder político local? Como pretendia assegurar o comportamento das pessoas em relação às questóes sanitárias? Além de refletir sobre essas questóes, este estudo associa o ideal de saúde pública ao processo de modernização da vida urbana brasileira, no final do séc. XIX e início do séc. XX através da experiência local de urbanização ocorrida em Divinópolis/MG. A legislação aprovada em 1913 pela Câmara Municipal de Divinópolis trouxe consigo um modelo idealizado de convívio social, baseado em novos valores urbanos e modernos, desejando superar a forma tradicional-rural de convívio social e de hábitos até então existentes, principalmente em relação às questóes sanitárias. A ênfase dada diz respeito aos comportamentos a serem exigidos da população urbana em relação à conservação ou restauração da saúde, higiene e medidas destinadas a preservar a saúde pública ou particular de tudo quanto poderia prejudicá-la, principalmente em relação à doenças endêmicas ou contagiosas.

\section{O SURgimento E ORganizaÇÃo da CIDAdE DE Divinópolis/MG}

O município de Divinópolis/MG foi criado em 30 de agosto de 1911 e a Câmara Municipal foi instalada em $1^{\circ}$ de junho de 1912. Para ordenar e planejar a ocupaçáo do espaço urbano da recém-criada Vila, a Câmara Municipal aprovou sua planta topográfica através da Lei no 03 de 20 de junho de 1912. Ela foi elaborada pelo engenheiro-chefe responsável pela construção do ramal ferroviário entre Belo Horizonte e Garças, Dr. José de Berrêdo, a pedido do Presidente da Câmara Sr. Antônio Olympio de Moraes. Das discussóes ocorridas entre eles surgiu a idéia de projetar a parte nova da Vila de acordo com um traçado geométrico, retilíneo, grandes quarteiróes formados por ruas e avenidas largas, evidenciando uma ordenação racional, funcional e moderna do espaço urbano, baseada numa expectativa de progresso futuro da localidade. A preocupação com a higiene, a saúde, a funcionalidade das vias urbanas, o planejamento da ocupação do espaço urbano pelas diferentes atividades, o controle sobre as condições das moradias e lazer são características da estética moderna de uma cidade con-

1 - VEIGA, 1994, p. 116 siderada progressista. [1]

Dentro dessa perspectiva de modernização urbana, a exemplo do que já tinha ocorrido na cidade de Belo Horizonte, é que foi aprovado, em 20 de novembro de 1912, o documento "Estatutos da Câmara Municipal da Villa Divinópolis" contendo também o seu Regimento Interno, constituído de 346 artigos. Esse documento possui várias partes e nesse estudo pretende-se analisar as prescrições em relação ao que chamamos hoje de saúde coletiva e evidenciar a política sanitária ali contida. Subliminarmente percebe-se um conteúdo educativo, até certo ponto autoritário, dessas prescriçóes visando adequar o comportamento dos indivíduos à vida urbana, desejando o rompimento com práticas rurais costumeiras e tradicionais de convívio e ocupação da cidade 
e aquisição de uma cultura urbana.[2] O Estatuto condenou várias atitudes da população com o objetivo de prevenir e reparar abusos que pudessem comprometer a saúde pública, definiu multas para os infratores e deu competência ao poder político local de exigir o cumprimento das normas aprovadas.

Divinópolis surgiu em 1912, a partir do antigo arraial do Espírito Santo do Itapecerica, existente desde meados do séc. XVIII. Em 1770 foi construída a Igreja Matriz. O censo demográfico de 1920 apurou a existência de 10.305 habitantes, sendo 3.826 na sede, nos perímetros urbano e suburbano, reunidos em 530 casas. Em 1923 a populaçáo da cidade era de aproximadamente 4.500 habitantes.[3]

O poder político local, nesse momento, era exercido pela Câmara Municipal e as funçóes executivas eram exercidas pelo Presidente da Câmara ou Agente Executivo, eleito por três anos pelos demais vereadores, que também elegiam o vice-presidente e secretário. A Câmara Municipal da Vila Divinópolis possuía 7 vereadores e uma secretaria que funcionava através da atuação de um diretor, tesoureiro, porteiro, contínuo, agentes municipais, zelador de água, do matadouro e cemitério. Os vereadores se dividiam em três comissóes permanentes: Leis, finanças e orçamento; Higiene, polícia e estatística; Obras e instrução pública, agricultura, comércio e indústria, atuando em mais de uma. A Câmara poderia eleger outras comissóes compostas ou não de vereadores.

O Agente Municipal desempenhava funçóes importantes na condução da política sanitária municipal em relação a vários aspectos. Ele deveria fiscalizar as casas de negócios, hotéis, açougues, padarias, fábricas, matadouro, prédios e terrenos particulares e demais locais onde fossem exigidas prescriçóes de higiene e asseio e verificar infrações ou inobservância das leis municipais em relação à higiene. Deveria inspecionar os vendedores ambulantes, não consentindo com a venda de alimentos que colocassem em risco a saúde pública. O Agente deveria acompanhar o alinhador e náo permitir a construção de obras sem a licença concedida pelo Presidente da Câmara e nem fora do alinhamento. Ele deveria indicar a necessidade de se demolirem obras ou construçóes que estivessem ameaçando desabar e embargar obras que estivessem sendo feitas fora das exigências municipais; deveria cuidar da proibição da presença de animais nas ruas e centro da povoação, conservação dos edifícios públicos, postes de iluminação, chafarizes e árvores.

\section{O ideal sanitário contido no $1^{\circ}$ Estatuto da Câmara Municipal}

\section{a) Sobre a higiene domiciliar [4]}

O Estatuto possuía características controladoras, pois permitia o exame das instalaçóes sanitárias existentes nas habitaçôes particulares ou coletivas pelos agentes municipais de saúde e competência para as devidas providências. As águas deveriam ser protegidas ficando proibido o corte de matas, estagnar ou fazer represa, embaraçar o escoamento de águas já utilizadas ou fazer escavaçôes. Proibiu, ainda, a instalaçáo de curtumes de couro ou fábrica que exalasse odores contaminando a atmosfera no perímetro urbano, bem como, inhumar ou enterrar corpos humanos fora do cemitério ou deixar insepulto por mais de 24 horas.

Considerou-se como infraçáo passível de multa jogar detritos nas ruas, praças e largos da Vila e dos distritos, jogar imundices, lixo ou animais mortos ou moribundos nos córregos, além do responsável ter que fazer a sua remoção.
2 - CORGOZINHO, 2003, p. $83 / 86$

3 - POLYANTHÉA, 1923, p. $17 / 18$

4 - QUINTA parte Da policia sanitária. In: Estatutos da Câmara Municipal da Villa Divinópolis" contendo o Regimento Interno. Belo Horizonte : Imprensa Official do Estado de Minas, 1913, artigos $n^{\circ}$ 283, 284 e parágrafos. p. $45 / 46$ 
5 - Idem cit. ant. artigos 285, a 289. p. 46

6 - Idem cit. ant. artigos 290 a 296, p. 47

7 - Idem cit. ant. artigos 297 a 302 , p. $47 / 48$
Proibiu-se, também, conservar nos pátios e quintais da área urbana as estrumeiras, ou seja, lugar de acúmulo, preparo e fermentaçáo de estrume para evitar o surgimento de miasmas ou mal-cheiro, incomodando a população. As latrinas teriam que ser construídas com sifăo com escoamento do esgoto ou tanque de coleta e as antigas, fora desse padrão, teriam que ser desfeitas.

\section{b) Sobre a alimentação pública [5]}

Em relação a este aspecto o Estatuto proibia a venda de bebidas falsificadas ou o acréscimo de substâncias para aumentar o peso, volume ou quantidade dos gêneros alimentícios; vender peixes ou toucinhos deteriorados, carne de animais mortos acidentalmente ou por veneno e carne de porco contaminada pela trichinella spiralis, que pode ser introduzida no organismo através da ingestão dessa carne.

Os agentes municipais de saúde poderiam inutilizar os gêneros considerados imprestáveis para o consumo, tanto aqueles expostos para venda como os que estivessem com vendedores ambulantes, com o auxílio da polícia se necessário e na presença do proprietário, mediante intimação. As frutas deterioradas também deveriam ser destruídas. O leite a ser comercializado náo poderia ser de vaca doente e nem alterado por qualquer substância, muito menos em vasilhas de cobre ou zinco. Para a venda de produtos alimentícios não poderiam ser contratadas pessoas com moléstia contagiosa ou repulsiva, com previsão de multa para o dono das mercadorias.

c) Sobre as precauçôes contra moléstias transmissíveis ou epidemias [6]

Os casos de moléstias endêmicas, suspeitas ou não de serem transmissíveis, teriam que ser notificadas ao Presidente da Comarca pelos médicos, gerentes de fábricas, diretores de colégios. As pessoas doentes deveriam ser isoladas em casa ou removidas para um lugar conveniente, sem especificar onde e o domicílio teria que ser desinfetado. Os responsáveis pelo doente náo poderiam se opor à sua retirada pelo representante municipal, que poderia, se necessário, usar a força policial e nem a se oporem a desinfetar o ambiente, sob pena de multa.

Nos casos de epidemia o Presidente da Câmara deveria requisitar o auxílio do Governo do Estado. As doenças que deveriam ser obrigatoriamente notificadas eram moléstias pestilentas como a febre amarela, chorela e peste do oriente, as febres epidêmicas como a varíola, escarlatina, sarampão e a difteria. Além disso, a Câmara teria que criar postos de vacinaçáo, cumprindo a Lei no 144 de 23 de julho de 1895. Nos casos de epidemias no município a Câmara deveria organizar enfermarias ou hospitais-barracas fora do perímetro das povoaçóes para a realização do isolamento dos doentes e desinfecção, sob a orientação do Delegado de Higiene do Estado ou do médico da municipalidade. Para tanto, o Presidente da Câmara poderia, até mesmo, tomar ele próprio essa decisão, no caso de urgência.

\section{d) Limpeza pública [7]}

O serviço de limpeza pública da Vila era constituído pela capinação, varredura das ruas, avenidas e praças e a remoção do lixo e animais mortos. Os restos de material de construção ou objetos deixados nas vias públicas devem ser retirados pelos donos ou responsáveis. $\mathrm{O}$ lixo das residências deveria ser entregue em dias determinados da semana e acondicionados em latas ou caixas depositadas de manhã junto dos portóes.

Os agentes municipais poderiam fazer a inspeção nas residências para verifi- 
car a existência de imundices ou objetos prejudiciais à saúde da população e obrigar o morador a fazer a remoção. O Estatuto também esclarecia que nenhum habitante poderia jogar nas ruas, avenidas e praças o lixo, cacos de vidro, palhas, papel, cascas de frutas, águas utilizadas e tudo que prejudicasse o livre trânsito e produzisse exalaçôes nocivas ou prejudiciais à limpeza das vias públicas. Os animais mortos deveriam ser enterrados pelos seus donos e no caso de não ser possível identificar o responsável, o agente municipal deveria tomar as providências cabíveis.

e) Sobre as medidas preventivas de dano [8]

Várias circunstâncias de risco são citadas no Estatuto. Em relação à questão sanitária, salienta-se a proibição de cães ou outros animais vagando pelas ruas, podendo ser mortos por ordem do agente municipal, escolhendo-se o modo menos bárbaro. A exceção referia-se aos cães perdigueiros, cães de caça atrelados dois a dois ou que trouxessem coleira em que se lesse o nome do dono que, por sua vez, teria que ter pago o registro do animal. Proibia-se, também, a criação, engorda ou manutenção de animais domésticos, com exceção de muares ou cavalos de cocheiras nos pátios ou chácaras no perímetro urbano.

No perímetro urbano, os animais só poderiam transitar atrelados ao carro ou conduzidos presos, ou boiadas em trânsito com exceção das vacas de leite ou bois de carro que estivessem sendo conduzidos do pasto ao curral, podendo atravessar ruas periféricas ou pequenos trechos. Os moradores da Vila teriam que extinguir os formigueiros de seus terrenos, sob pena de multa ou intervenção do agente administrativo. A responsabilidade da Câmara em relaçáo aos formigueiros era de retirá-los dos terrenos públicos ou de terrenos de pessoas indigentes.

$\mathrm{O}$ donos das tavernas não poderiam vender bebidas alcoólicas a menores de idade ou pessoas que estivessem em princípio de embriaguez. Ébrios e loucos mentecaptos eram considerados capazes de causar danos à população. $\mathrm{O}$ Estatuto recomendava que eles fossem detidos e entregues pelo agente municipal à polícia correcional, entregues aos seus responsáveis e, em falta desses, seriam enviados a estabelecimentos de caridade pública. Proibia-se, também, a atividade de esmolar, com exceção pelos hospitais, asilos, irmandades que tivessem licença e contribuiçóes para as festas religiosas.

\section{f) Sobre os mendigos [9]}

No Estatuto consta a seguinte definição de mendigo: "será considerado mendigo o que implorar esmolas por não poder ganhar a subsistência por trabalho ou por não ter recursos próprios, nem parentes nas condiçóes de lhe prestar alimentos, nos termos da lei civil." [10] A mendicância era regulamentada pelo poder municipal. Para esmolar na Vila, a pessoa teria que se inscrever como mendigo no livro da Polícia ou na Secretaria Municipal, podendo ser obtida de forma solicitada voluntariamente ou coercitiva por decisão de uma autoridade policial ou a mando do Presidente da Câmara. Dessa forma, era feito o registro individual e numérico dos mendigos e esclarecimentos sobre sua identidade: nome, idade, filiação, naturalidade, estado civil, residência.

Sem inscrição prévia, os mendigos encontrados seriam detidos e examinados para verificação de sua capacidade ou não para o trabalho. Os mendigos de fora da Vila ou que não possuísse família ou residência no lugar há mais de dois anos seriam mandados de volta para seu município de origem junto com um ofício explicativo para a autoridade policial.
8 - Idem cit. ant. artigos $303 / 312$, p. $49 / 50$

9 - Idem cit. ant. artigos 319/325, p. 52.

10 - idem cit. ant. artigo 319 , p. 52. 
A inscrição gerava direitos para os mendigos, definindo o local e horário permitidos para a mendicância e estabelecia deveres como o de portar o bilhete de identidade e náo mendigar fora do local e dia permitidos, caso contrário poderiam ser presos, o que também poderia ocorrer se portasse o bilhete de outro mendigo. Vários outros comportamentos eram também proibidos como cantar ou fazer barulho, exibir deformidades ou feridas ou ter a companhia de outras pessoas a não ser pai, mãe, marido ou filhos. Os mendigos menores de 21 anos seriam presos e entregues para as pessoas responsáveis.

11 - idem cit. ant. artigos $155 / 164$, p. $21 / 23$

12 - idem cit. ant. artigos $155 / 164$, p. $21 / 23$

\section{g) Sobre o abastecimento de água [11]}

Através das normas sobre o abastecimento de água na Vila Divinópolis, contidas no Estatuto da Câmara Municipal, é possível perceber que o poder público local era o responsável pelo oferecimento da água para a população por meio de chafarizes ou nas residências, de forma encanada, mediante pagamento da pena d'água. Para receber a água, o proprietário deveria conservar o encanamento, consertar torneiras e responsabilizar-se pelo seu mal uso, como o desperdício com torneira aberta, escorrendo e prejudicando o trânsito público, sujeira ou aumento do orifício do registro da pena d'água, que também não poderia ser dividida com vizinhos. As pessoas que causassem danos aos encanamentos públicos ou prejudicassem o asseio dos chafarizes ou reservatórios, mesmo que involuntariamente, teriam que pagar multas e responsabilizar-se pelo conserto.

Para cuidar do abastecimento d'água, foi criado o cargo de zelador nomeado pelo Presidente da Câmara. O zelador deveria conservar os encanamentos e o asseio dos reservatórios e nascentes. Deveria fazer a descarga e lavagem do reservatório, com intervalo de quinze dias, avisando previamente ao público por editais e informar ao agente executivo as novas concessôes de penas d'água. O zelador não poderia deixar a Vila sem água encanada por mais de vinte e quatro horas, sem a devida justificativa ou deixar no reservatório objetos que viessem a alterar a qualidade da água, sob pena de multa ou perda do seu pagamento mensal.

\section{h) Sobre o matadouro [12]}

O abastecimento de carne de gado para a população teria que ser realizado através do matadouro municipal. Fora do matadouro só era permitido "abater-se cevado para o consumo particular" mediante licença do Presidente da Câmara, segundo o parágrafo único do artigo 165 do Estatuto.

O prédio do matadouro deveria possuir água canalizada, os utensílios necessários ao abate do gado, currais distintos, com inclinação para o escoamento dos líquidos, telheiros e tanques. Se não fosse possível fazer um contrato de acordo com a legislaçáo municipal vigente, o Presidente da Câmara poderia dar a preferência para a matança ao açougueiro ou marchante que tivesse pago a licença e que oferecesse melhor preço, maior qualidade da carne e vantagens para o público. Essa preferência deveria ser oficializada em termo lavrado na Secretaria, por prazo máximo de um ano e sem prejuízo da liberdade de comércio para os demais. Essa preferência poderia ficar perdida se o contemplado cometesse alguma infração em relação ao Estatuto. A matança de porcos, carneiros ou cabritos deveria ser feita antes do gado vaccum, segundo o Estatuto e as vísceras dos animais abatidos deveriam ser imediatamente colocadas em vasilhas próprias para serem conduzidas ao seu destino. $\mathrm{O}$ couro de animais não poderia ser espichado ou posto para secar dentro da área da povoação. 
A gado para ser abatido não poderia permanecer em pátios ou currais particulares sob pena de multa. $\mathrm{Na}$ área suburbana poderiam existir currais para a criação de porcos, desde que arejados e limpos, com inclinação necessária para o escoamento das águas usadas e tanque de d'água permanente. $\mathrm{O}$ gado a ser abatido não poderia ser maltratado ou espancado, não poderia estar prenhe ou com suspeita de doenças ou sob efeito de ervas e os bois teriam que ser castrados. A responsabilidade de verificação diária da situação do gado a ser abatido era do zelador do matadouro. Além de verificar a situação do gado em pé ele também deveria fiscalizar a carne antes de ser enviada para os açougues. Para serem abatidos e esfolados os animais deveriam ser suspensos em ganchos, tomando-se o cuidado de impedir o contato entre a parte peluda e vísceras com a carne. Os cuidados se estendiam à sua comercialização em açougues ou em domicílios, sendo que, para isso, a carne deveria ser coberta com pano para não ficar exposta às moscas. O zelador do matadouro deveria assistir ao abate todos os dias até a saída das carnes e não permitir a presença de pessoas estranhas no local, principalmente, de crianças. Deveria, ainda, impedir a entrada de cáes e cuidar do asseio dos currais e dependências.

Pessoas com moléstias contagiosas ou repugnantes não poderiam vender alimentos ou empregar-se no comércio. As infrações seriam punidas com multas.

\section{i) Sobre os açougues [13]}

O Estatuto fazia numerosas exigências para a abertura de açougue. As salas deveriam ter o chão impermeável, com escoamento para água, revestido de azulejo até a altura de dois metros e meio e parede pintada a óleo. Os açougues deveriam ser bem ventilados com grades de ferro nas janelas e portas. As mesas de corte das carnes deveriam ser de mármore ou pedra plástica sendo fiscalizadas pelo zelador. Para terem permissão de abertura de açougue os açougueiros deveriam manter seu estabelecimento em completo asseio; náo poderiam misturar com outro ramo de negócios ou até mesmo, dormitório. No local não poderia entrar cáes, as carnes deveriam ficar suspensas de modo afastado das paredes e sem receber raios solares. Às duas da tarde a carne que náo fosse vendida teria que ser salgada e aquelas em início de decomposição teriam que ser inutilizadas.

\section{j) Sobre as construções urbanas e vias públicas [14]}

Todas as obras nas praças, largos, ruas ou avenidas teriam que ser feitas de acordo com o plano geral e alinhamento estipulado pela planta topográfica da Vila, aprovada pela Câmara Municipal e permissão do Presidente da Câmara. O responsável para cuidar dessa exigência e fazer cumprir o planejamento era o alinhador, nomeado pelo Presidente e remunerado pelo proprietário da obra. Dever-se-ia alinhar ou perfilar o edifício, casa ou obra em geral conforme o arruamento estabelecido. A planta da construção teria que atender às normas arquitetônicas e de higiene definidas, e ser aprovada pelo Presidente da Câmara. Os prédios rústicos poderiam ser construídos em algumas ruas, sendo proibida a construção de choupanas cobertas de capim ou zinco. Os edifícios que estivessem fora do alinhamento geral teriam que sujeitar-se ao novo alinhamento e conveniências de embelezamento, quando tivessem que ser reconstruídos. As casas recuadas deveriam possuir gradil e a área entre a casa e o gradil deveria ser ajardinada. Não era permitido fazer escavaçôes ou depósito de materiais de construção nas ruas e praças sem licença do Presidente da Câmara. As construçóes
13 - idem cit. ant. artigos $165 / 181$, p. $13 / 25$

14 - idem cit. ant. artigo 230/258, p.36/39, 43 
não poderiam ter janelas, terraços, varandas ou sótáo para os lados, devassando as casas dos vizinhos, com menos de dois metros de distância e não poderiam construir telhados que desaguassem em terrenos ou casas dos vizinhos ou sacadas de madeira. As construçôes teriam que ter quatro metros de pé direito, ou seja, altura interna.

O Estatuto proibia, ainda, a existência na Vila de cortiços, estalagens, casas para moradias coletivas, sob qualquer denominação que não possuíssem as condiçóes exigidas para os hotéis. As casas deveriam ser pintadas em cores, sendo proibida a simples caiação ou pintura branca e sempre com pinturas renovadas quando estivessem com aspecto desagradável. O Presidente poderia intimar os proprietários dos prédios a cumprirem essa exigência, além da cobrança de multas. Na zona urbana não era permitida a abertura de cisternas e as existentes teriam que ser entupidas.

Os terrenos urbanos teriam que ser fechados com gradis ou muros de adobe, tijolos, barro ou pedra, rebocados e pintados a cores. O proprietário de terreno em plano inferior ao do vizinho teria que consentir a passagem de águas pluviais e encanamento de águas e esgotos, derivados de terrenos mais elevados. Todo proprietário na zona urbana teria que mandar construir passeios na via pública em toda a frente do terreno, sob pena de multa e dentro de normas técnicas, tamanho, altura e largura definidos no Estatuto, além da obrigação de dar manutenção e mantê-los conservados.

O Presidente da Câmara deveria fazer o prolongamento, alargamento ou abertura de ruas à medida que fossem consideradas de utilidade pública ao embelezamento da Vila. Para tanto, ele deveria entrar em acordo com os proprietários, e se esses se opusessem, poderia fazer a desapropriação da área necessária de acordo com a legislação estadual vigente. Deveria, ainda, cuidar do calçamento, limpeza e conservação por meio de contrato ou administraçáo; mandar numerar as casas e colocar placas nas ruas, conservando seus nomes tradicionais.

\section{O CORPO POLÍTICO: SANEAMENTO E BELEZA}

A quem as normas do Estatuto de 1913, aprovado pela Câmara Municipal de Divinópolis/MG pretendiam atingir? De um lado, podemos considerar que o objetivo seria atingir e modificar uma população, até então rural, impregnada de valores de uma vida tradicional. De outro lado, é uma legislaçáo que quer dar legitimidade e suporte legal para uma sociedade de indivíduos que se entrelaçam em atividades e interesses diferenciados. As normas estatutárias deixam entrever o desejo por uma vida urbana planejada e organizada pelo poder público local, assentada em um olhar punitivo, sem sujeiras, saneada de animais, doentes, loucos e ébrios e busca de uma cidade bela não só pelas formas arquitetônicas e cores dos edifícios e muros, mas pelo alinhamento das construçóes e crescimento retilíneo de suas vias públicas. Uma sociedade urbana sã pelo asseio dos espaços públicos, construções, edifícios, atividades econômicas, fornecimento de alimentos, encaminhamento dos doentes e superação de hábitos tradicionais considerados sujos ou mal cheirosos. A feiúra dos mendigos na cidade também ficaria saneada, através das medidas de controle quanto aos lugares, horários e formas de mendigar. Essa utópica beleza seria o resultado qualitativo das açôes dos indivíduos e garantidas através de puniçóes.

15 - CARVALHO, 2002, p. $105 / 113$

Segundo José Murilo de Carvalho [15] existem três versôes clássicas da tradição democrática ocidental. A primeira é o conceito liberal de cidadania 
como titularidade de direitos e corresponde à liberdade negativa dos modernos:

cuja finalidade principal era livrar os indivíduos dos constrangimentos legais e institucionais a fim de poderem dedicar-se totalmente à vida civil, ao apetite aquisitivo da sociedade utilitária de mercado. (CARVALHO, 2002: 105)

A segunda versão é a do republicanismo clássico ou humanismo cívico em que:

enfatiza a preocupação com a res publica, com o bem coletivo, mesmo que isto exija o sacrifício do interesse individual. A preocupação com o bem coletivo é a virtude cívica ... disponibilidade do cidadão para se envolver diretamente na tarefa do governo da coletividade. (Idem: 105)

A terceira versão refere-se a uma visão comunitária de cidadania:

Importa aqui o sentimento de pertencimento a uma comunidade política ... enfatiza o coletivo em detrimento do individual. No entanto, ela não é necessariamente virtuosa, na medida em que lhe falta a ênfase na ação política, na participação do cidadão na vida pública. A ênfase exclusiva na comunidade pode gerar ... a conformidade política, ou uma participação passiva... (Ibidem: 106)

Segundo Carvalho, a cultura política brasileira não parece enquadrar-se em nenhuma das versóes que marcaram a tradição ocidental. Por outro lado, se considerarmos essas versóes como modelos idealizados, visando o surgimento de uma dada cidadania é possível associar, mesmo que de forma geral, essa terceira versáo de cidadania ao ideal de vida comunitária almejado na organização da vida urbana municipal no início do séc. XX em cidades brasileiras, pois é possível que o documento "Estatutos da Câmara Municipal da Vila Divinópolis contendo o Regimento Interno" tenha sido elaborado a partir de um modelo importado de outras experiências urbanas. Como averiguar sua fonte não é objetivo desse estudo, vamos nos ater ao ideal de vida urbana contido nas entrelinhas do documento citado.

Podemos considerar que a aplicação das normas estatutárias citadas anteriormente quisesse criar uma situação de pertencimento a uma comunidade política, em que o interesse coletivo estivesse acima do individual. Nesse caso específico visando o abandono de hábitos e atitudes típicas do mundo rural-tradicional e adoção de comportamentos modernos e impregnados de uma visão sanitarista. Exemplificando: as normas do Estatuto proibiam o trânsito de animais nas vias públicas urbanas, criação de porcos nos quintais, currais, curtume, cisternas etc. muito comuns em cidades que não se urbanizaram.

O poder municipal é o grande organizador da vida coletiva, colocando-se como o articulador político fundamental, permitindo e assegurando a vida social 
urbana com poder de punição e de interferência no âmbito privado, em relação aos aspectos que estivessem prejudicando os interesses coletivos. Além das exigências, claramente definidas no Estatuto, as desobediências seriam multadas e, se tais exigências, não fossem atendidas, a adequação seria executada por ordem do Presidente da Câmara, ficando o proprietário obrigado a pagar as despesas para os cofres públicos. Todas as normas indicam não só o que não pode ser feito, como também estipula as multas correspondentes no caso de desobediência civil. Não há referência a direitos, o que fica subentendido é que ao ser assegurada a forma de vida idealizada, o ganho é de todos, na medida em que prevalecerem os interesses coletivos e não individuais.

Em nenhum momento nesse Estatuto há o uso da palavra cidadáo para se referir aos habitantes da cidade. Eles aparecem no texto através de expressões como: proprietários, moradores, donos, infratores, pessoas, autoridades, funcionários e empregados municipais, concessionários, vendedores, compradores, contribuintes, mercadores ou mascates, indivíduos, profissionais, negociantes ou construtores. As normas não desejam a participação política dos habitantes, apenas o seu cumprimento, controlando as atitudes individuais, através da possibilidade de multas. A cidadania desejada é, em sua forma passiva, sem contestação e sem colocar em risco o pertencimento a essa comunidade política sã e bela que vai resultar das atitudes de cada indivíduo em conformidade com as normas. Qualquer obstáculo, pessoas, objetos ou coisas que pudessem trazer desequilíbrio a esse modelo de vida urbana deveriam ser descartadas: os animais, os ébrios, os loucos e os doentes.

Arriscaríamos dizer que esse comportamento político é próprio de uma sociedade onde predomina o mando de oligarquias que definem a forma de vida que os indivíduos devem adotar e os seus lugares na hierarquia social e não a isonomia. Portanto, o que fica subentendido é o predomínio de uma concepção política centralizadora e punitiva distante dos ideais democráticos, tanto aqueles associados ao liberalismo quanto ao humanismo cívico da res publica.

Mesmo que a população urbana de Divinópolis/MG fosse ainda muito reduzida no início do séc. XX, e reunida em poucas casas é pouco provável que o poder público local, através de seus funcionários, conseguissem exercer um controle efetivo sobre o comportamento da população urbana, cuja tendência era de um contínuo crescimento pela atraçáo econômica exercida sobre as pessoas de cidades vizinhas. Para tanto seria necessário verificar documentos que tenham registrado o recebimento de multas. De qualquer modo, o dinamismo comercial e as atividades industriais nascentes no local, acrescidas pelo crescimento demográfico ocorrido nos leva a especular que as relaçôes sociais se tornaram mais complexas e, portanto, mais difíceis de serem controladas pelo poder político municipal em Divinópolis/MG. Isso se torna ainda mais plausível, se considerarmos, que a população atraída pelo desenvolvimento dessa cidade era oriunda de regióes vizinhas caracterizadas por um modo de vida tradicional-rural. Os hábitos e costumes de uma cultura tradicional-rural não se modificam nos indivíduos simplesmente em decorrência de normas legais e ameaças de punição. Eles demoram muito tempo para serem enfraquecidos e superados. O que ocorre, no cotidiano das pessoas, é a introduçáo lenta de novos valores e o convívio entre formas tradicionais e modernas de vida social. [16] 


\section{CONSIDERAÇÓES FINAIS}

A experiência de construção de vida urbana ocorrida na cidade de Divinópolis/MG é, apenas, um exemplo do que ocorreu em muitas outras localidades de Minas Gerais, enquanto manifestação de um processo geral de implantação de vida urbana no Brasil. De qualquer modo, essa experiência mostra o quanto, desde o início de implantaçáo dos processos modernos de vida urbana no local, ficamos distantes dos ideais democráticos de participação política, conquista de direitos e identificação do habitante da cidade como cidadão.

Os resultados efetivos das normas estatutárias citadas, na vida cotidiana daqueles habitantes, não corresponderam ao idealizado. Pode ser que jornais locais e outros documentos, principalmente em relação às multas aplicadas contenham indícios das circunstâncias e contradiçóes que normalmente se manifestam na vida social, em decorrência dos atos administrativos legais. Entretanto, o modo de vida urbano e moderno existente na cidade de Divinópolis/MG na atualidade e o comportamento político de seus habitantes talvez sejam a maior evidência do distanciamento entre o idealizado e enraizado no comportamento dos habitantes. Desde muito tempo, as relaçóes sociais existentes nessa cidade não são mais passíveis de controle como nos moldes idealizados devido sua amplitude e diversificação. O exercício da cidadania enquanto participação efetiva dos cidadãos no processo político e conquista de direitos continuam sendo um ideal a ser alcançado e principalmente um desafio, dadas as influências enraizadas nas consciências individuais dos processo políticos centralizadores vividos anteriormente.

\section{REFERÊNCIAS BIBLIOGRÁFICAS}

BENDIX, R. "Tradição e modernidade reconsideradas". In: National-building and citizenship: studies of our changing social order. Los Angeles : University of California Press, 1977.

CARVALHO, José Murilo. "Cidadania na encruzilhada". In: BIGNOTTO, Newton. Belo Horizonte/MG : Edit. UFMG, 2002.

CORGOZINHO, Batistina Maria de Sousa. Continuidade e ruptura nas linhas da modernidade: a passagem do tradicional ao moderno no centro-oeste de Minas Gerais. Divinópolis/MG : FUNEDI, 2003.

ELIAS, Norbert. A sociedade dos individuos. Rio de Janeiro : Jorge Zahar Edt. Rio de Janeiro, 1994.

ESTATUTOS da Câmara Municipal da Villa Divinópolis cotendo o Regimento Interno. Belo Horizonte : Imprensa Official do Estado de Minas Gerais, 1913.

FOUCAULT, Michel. Vigiar e punir. Petrópolis : Vozes, 1986.

LEFEBVRE, Henri. A revolução urbana. Belo Horizonte/MG : Ed. UFMG, 2004.

RIBEIRO, Luiz César de Queiroz \& PECHMAN, Robert. Cidade, povo e nação: gênese do urbanismo moderno. Rio de Janeiro : Civilizaçáo Brasileira, 1996.

POLYANTHÉA em Homenagem ao Excellentíssimo e Reverendíssimo Senhor Dom Antonio dos Santos Cabral, 1o Bispo de Bello Horizonte: por occasião de sua primeira visita pastoral a parochia de Divinópolis, sendo vigário o Revmo. Sr Padre Jose Augusto d. Bicalho, 1923.

VEIGA, Cynthia Greive. "Cidadania e educação na trama da cidade: a construção de Belo Horizonte em fins do séc. XIX”. Campinas: Universidade Estadual de Campinas, 1994 (Tese, Doutorado em História). Mimeo. 